\title{
INTERPRETIVE SUMMARIES, OCTOBER 2011
}

Microbial dynamics during the ripening of a mixed cow and goat milk cheese manufactured using frozen goat milk curd. By Campos et al., page 4766. Mixed (cow, goat, and ewe) milk cheeses account for $40 \%$ of Spanish cheese production. To overcome the shortage of goat milk in summer and autumn, pasteurized goat milk curd or high-pressure-treated raw goat milk curd manufactured in spring were held at $-24^{\circ} \mathrm{C}$ for 4 mo, thawed, and mixed with fresh cow milk curd for the manufacture of experimental cheeses. Control cheeses were made from a mixture of pasteurized cow and goat milk. Culture-dependent and culture-independent techniques showed a higher Lactobacillus population in experimental cheeses than in control cheeses throughout the ripening.

Composition and effect of blending of noncoagulating, poorly coagulating, and well-coagulating bovine milk from individual Danish Holstein cows. By Frederiksen et al., page 478\%. Noncoagulating (NC) milk was consistently observed in $4 \%$ of cows in a screening study of 53 Danish Holstein dairy cows. The NC milk contained a higher fraction of more phosphorylated variants of $\alpha$-caseins. Blending NC milks into well-coagulating milk compromised the quality of the latter, with clear effects at $25 \% \mathrm{NC}$ milk. The clotting properties of NC milk were improved by addition of $0.005 \%$ calcium, although not to the level of well-coagulating milk. A potential genetic contribution to NC milk gives strong perspectives for inclusion of coagulation properties as a parameter in future breeding programs.

Development of a rapid method for the measurement of lactose in milk using a blood glucose biosensor. By Amancharla and Metzger, page 4800. A rapid and simple method was developed for routine determination of the lactose content of milk. The method is based on hydrolysis of lactose using $\beta$-galactosidase and subsequently measuring glucose using a blood glucose meter. The glucose meter reading was then used to calculate the lactose content. Initially, the proposed method was standardized using model solutions. Subsequently, 10 raw milk samples were measured for lactose concentration using the proposed method and a reference method. The glucose meter method can be used as a low-cost method for routine analysis of lactose in milk. The cost of the supplies to conduct a single test is $\$ 0.40$ for one test strip and a one-time cost of approximately $\$ 10.00$ for the blood glucose meter.

Determination of 10-hydroxystearic, 10-ketostearic, 8-hydroxypalmitic, and 8-ketopalmitic acids in milk fat by solid-phase extraction plus gas chromatography-mass spectrometry. $B y$
Márquez-Ruiz et al., page 4810. In dairy products little is known about the occurrence of fatty acids (FA) bearing oxygenated functions and present in esterified form in triacylglycerols. A method based on gas chromatography previously used for isolation of polar FA by solid-phase extraction was applied to determine these FA in milk fat. Milk samples obtained from goats and ewes fed with a variety of oil sources were studied. 8-Ketopalmitic, 8-hydroxypalmitic, 10-ketostearic, and mainly 10-hydroxystearic were measured. The highest levels of 10-ketostearic acid were obtained in milk from animals fed olive oil, and 10-hydroxystearic acid, not previously reported in milk, was the second most abundant oxygenated FA.

The role of copper in the manufacture of Finnish Emmental cheese. By Mato Rodriguez et al., page 4831. The production of Emmental cheese is economically very important for the Finnish dairy industry. Its manufacture may vary depending on the place of origin. Production of Swiss Emmental utilizes copper vats. In Finland, the standard Emmental cheese manufacture includes a supplement of $\mathrm{Cu}$ as copper sulfate $\left(\mathrm{CuSO}_{4}\right)$ salt in cheese-milk in order to achieve the same level of copper as when this cheese is produced in copper vats. Only a few studies have been published on the effects of $\mathrm{Cu}$ on the microorganisms that are utilized for Emmental production and none focused on Finnish Emmental.

Effect of sodium gluconate on the solubility of calcium lactate. By Phadungath and Metzger, page 4843. Calcium lactate crystals are a common defect in Cheddar cheese. This study determined if sodium gluconate could increase the solubility of calcium lactate in model solutions. After $21 \mathrm{~d}$ of storage at $7^{\circ} \mathrm{C}$, the presence of sodium gluconate increased the solubility of calcium lactate. Sodium gluconate could be used to prevent formation of calcium lactate crystals in Cheddar cheese.

Short communication: Preliminary investigation into the effect of freezing and a cryopreservant on the recovery of mastitis pathogens from ewe milk. By Smith et al., page 4850. Freezing sheep milk prior to microbiological analysis might reduce the probability of detecting mastitis pathogens. Although culture of a fresh milk sample is optimal, the addition of glycerol to milk before freezing might improve recovery of bacteria by offering protection to gram-negative isolates.

Flexible and fixed partitions in freestalls-Effects on lying behavior and cow preference. $B y$ Ruud and Bøe, page 4856. In a controlled study with 16 nonlactating dairy cows, freestalls with flexible stall 
partitions were compared with stalls with solid cantilever pipeline partitions. We evaluated behavior, lying position, stall cleanliness, and cow preferences. No differences in lying time, lying position, or stall cleanliness were found. In the preference test, cows preferred the stalls with flexible stall dividers when lying in the stalls.

The effect of recurrent episodes of clinical mastitis caused by gram-positive and gram-negative bacteria and other organisms on mortality and culling in Holstein dairy cows. By Hertl et al., page 4863. This study estimated effects of recurrent cases of clinical mastitis due to gram-positive and gram-negative bacteria and other organisms occurring in 30,233 lactations on probability of death and sale for cows in 7 New York Holstein herds. Generalized linear mixed models were used. Herd, parity, lactation month, year, season, economic variables, the first 3 mastitis cases in a lactation, and other diseases were included. Primiparous and multiparous cows were analyzed separately. Mastitis, regardless of type, increased probability of both death and sale; the effect of case severity was undetermined. Gram-negative mastitis generally carried the greatest risk for death and sale.

A study on cow comfort and risk for lameness and mastitis in relation to different types of bedding materials. By van Gastelen et al., page 4878 . When cows are housed in a comfortable environment, they appear to be more profitable. Cows respond to a stressful and uncomfortable environment in ways that reduce their health, productivity, and welfare. The comfort of freestalls depends on the type and quality of the bedding material. This study provides data on the effect of the bedding materials box compost, sand, horse manure, and foam mattresses on cow comfort and health. Overall, sand provided a comfortable lying surface with a low bacterial count, whereas the other materials scored lower on lying comfort or bacterial count.

When and where do dairy cows defecate and urinate? By Villettaz Robichaud et al., page 4889. Defecation and urination were investigated in 77 lactating Holstein cows. Cows differed in frequencies of defecation and urination, but these differences were not related to physical and production traits. Little diurnal variation was found in when cows defecated or urinated. Cows sometimes defecated and urinated while lying down and often after standing up. Approximately $27 \%$ of defecations and $40 \%$ of urinations happened while cows were occupying a stall.

The association of serum metabolites with clinical disease during the transition period. $B y$ Chapinal et al., page 489\%. A total of 2,365 dairy cows from 55 freestall herds in North America were blood- sampled $1 \mathrm{wk}$ before and $1 \mathrm{wk}$ after calving to validate the relationship between serum nonesterified fatty acids (NEFA), $\beta$-hydroxybutyrate, and calcium concentrations and disease in early lactation. Elevated serum NEFA concentrations within 1 wk before calving were associated with increased risk of retained placenta, metritis, and displaced abomasum after calving. Elevated NEFA and decreased calcium serum concentrations in combination in the $2 \mathrm{wk}$ around calving were associated increased risk of displaced abomasum.

First report about the mode of action of combined butafosfan and cyanocobalamin on hepatic metabolism in nonketotic early lactating cows. By Kreipe et al., page 4904. Combined application of butafosfan and cyanocobalamin on hepatic gene expression in early lactating cows was evaluated. Treatments included an intravenous application of combined butafosfan and cyanocobalamin ( $\mathrm{TG}, \mathrm{n}=8$ ) or a placebo ( $\mathrm{CG}, \mathrm{n}=8$ ) on $3 \mathrm{~d}$ consecutively at $25 \mathrm{~d}$ in milk. The mRNA abundance of acyl-CoA-synthetase long-chain family member 1 was lower in TG compared with CG. In conclusion, combined butafosfan and cyanocobalamin affects mRNA abundance of genes in the bovine liver.

Neither bovine somatotropin nor growth hormone releasing factor alters expression of thyroid hormone receptors in liver and mammary tissues. By Capuco et al., page 4915. It has been hypothesized that growth hormone increases milk production by reallocating nutrients toward the mammary gland. Establishing this metabolic priority to support lactation may be facilitated by the actions of thyroid hormones. Thyroid hormone action in a tissue may be influenced by local alterations in thyroid hormone metabolism or by changes in the number or affinity of thyroid hormone receptors. In the present study, bovine growth hormone or growth hormone-releasing factor was administered to lactating cows and the effects on expression of thyroid hormone receptors in the liver and mammary gland were studied. Treatments did not alter the total number or affinity of thyroid hormone receptors in the liver or mammary gland, and did not alter the quantity of the alternative forms of thyroid hormone receptor that are expressed in the mammary gland.

Effect of dry period management on mammary gland function and its endocrine regulation in dairy cows. By Bernier-Dodier et al., page 4922. We investigated how a short dry period reduces subsequent milk production. The effect on milk production appears to be due to a reduced number of mammary cells. Higher levels of prolactin in lactating cows during late gestation could be involved in this process. Approaches that would accelerate mammary gland renewal during 
the dry period might overcome the negative effect of a short dry period on the subsequent lactation.

Economic feasibility of converting cow manure to electricity: A case study of the CVPS Cow Power program in Vermont. By Wang et al., page 4937. A case study of the Central Vermont Public Service Corporation (CVPS) Cow Power program examined the economic feasibility for dairy farms to convert cow manure into electricity via anaerobic methane digestion. We confirmed that it is technically feasible to convert cow manure to electricity on dairy farms but the economic returns depend highly on the base electricity price paid by CVPS, premium rate paid by CVPS customers, financial support from government agencies and other organizations, and sales of the byproducts of methane generation. Lessons learned from this program will be useful to other dairy farms and communities interested in converting cow manure into electricity.

Simple analytical and experimental procedure for selection of reference genes for reverse transcription quantitative PCR normalization data. By Manjarin et al., page 4950. Reverse transcription quantitative polymerase chain reaction (RT-qPCR) is the most common method for measuring gene expression. However, the accuracy of results is dependent on the invariant expression of genes used as normalization factors (i.e., reference genes). The objective of this study was to test a novel analytical protocol for selection of suitable reference genes for RT-qPCR by accounting for factors that are external to the $\mathrm{RT}-\mathrm{qPCR}$ reaction. The proposed analytical protocol represents a valid alternative to available methods for reference gene selection.

An unusual distribution of the niacin receptor in cattle. By Titgemeyer et al., page 4962. In cattle, pharmacological doses of niacin, an agonist for GPR109A (niacin receptor), were anorexigenic. Tissue distribution of GPR109A was investigated in cattle. Niacin receptor transcript and protein were detected in liver, muscle, and adipose tissues, and mRNA for GPR109A was found in bovine brain tissue. This identification of GPR109A in bovine liver, muscle, and brain is novel and may explain hypophagic responses of cattle to pharmacological doses of nicotinic acid.

Intermittent parenteral administration of endotoxin triggered metabolic and immunological alterations typically associated with displaced abomasum and retained placenta in periparturient dairy cows. By Zebeli et al., page 4968. We tested the hypothesis that intermittent endotoxemia, induced experimentally by 6 intravenous infusions of 3 increasing doses of lipopolysaccharide during the periparturient period, lowers feed intake and milk production during the first month postpartum. Furthermore, periparturient endotoxemia elicited changes in plasma metabolites and hormones related to energy, lipid metabolism, and stress as well as on minerals and immune variables. All of these changes were associated with a greater number of cows affected by left displaced abomasum and retained placenta.

Reproductive performance of grazing dairy cows following presynchronization and resynchronization protocols. By Ribeiro et al., page 4984. Grazing systems benefit from a large proportion of cows becoming pregnant early in the breeding season. A strategy to improve pregnancy to timed insemination is presynchronization of the estrous cycle; however, presynchronization based solely on prostaglandin $\mathrm{F}_{2 \alpha}$ has limited benefits to anovular cows. The use of gonadotropin-releasing hormone for presynchronization improved fertility of cows starting the timed insemination with progesterone $<1 \mathrm{ng} / \mathrm{mL}$, whereas Presynch benefited cows with progesterone $\geq 1 \mathrm{ng} / \mathrm{mL}$. Incorporation of a progesterone insert during resynchronization altered the pattern of return to estrus, but it did not benefit the reproductive performance of grazing dairy cows.

Effects of gonadotropin-releasing hormone at initiation of the 5-d timed artificial insemination (AI) program and timing of induction of ovulation relative to $\mathrm{AI}$ on ovarian dynamics and fertility of dairy heifers. By Lima et al., page $499 \%$. Optimizing the 5-d timed artificial insemination (AI) program to synchronize ovulation of dairy heifers allows producers to incorporate timed insemination when needed with acceptable fertility. The first gonadotropin releasing-hormone $(\mathrm{GnRH})$ of the protocol resulted in a low ovulation rate, and heifers that ovulated had reduced corpora luteum regression with a single prostaglandin treatment. Thus, GnRH did not benefit fertility of dairy heifers. On the other hand, extending proestrus by administering GnRH concurrent with insemination at $72 \mathrm{~h}$ after prostaglandin improved pregnancy per AI in heifers not displaying signs of estrus at AI.

Effect of exogenous somatotropin in Holstein calves on mammary gland composition and proliferation. By Huderson et al., page 5005. Regulation of mammary gland growth and development in calves is poorly understood but exogenous growth hormone is known to stimulate proliferation of mammary ducts in older heifers. We evaluated the effect of exogenous growth hormone on mammary gland development in young calves. Treatment with growth hormone decreased expression of growth hormone receptor and an epithelial cell proliferation marker, but mass of 
mammary parenchyma was not affected by treatment. However, treatment did affect mammary fat pad composition, which may influence subsequent development.

Temporal changes in plasma concentrations of hormones and metabolites in pasture-fed dairy cows during extended lactation. By Marett et al., page 501\%. Cows in pasture-based systems have varied capacity to complete extended lactations. Restricted intake after $300 \mathrm{~d}$ in milk decreased milk production but did not alter a cow's ability to complete a 670-d lactation or the profile of plasma hormone and metabolite concentrations. Increased plasma concentrations of leptin, insulin, and glucose and decreased concentrations of growth hormone in the second half of the lactation were consistent with greater nutrient partitioning towards adipose tissue at the expense of milk production. Profiles of cows able to reach the 670-d target indicated greater partitioning of nutrients towards the mammary gland than cows that milked $<600$ d.

The ability of common mastitis-causing pathogens to survive an ensiling period. By PeterssonWolfe et al., page 502\%. The present study demonstrates the ability of mastitis-causing bacteria to survive the ensiling process, a commonly used forage preservation method used for dairy cattle. Following the application of a bacterial starter culture and 3-wk fermentation process, streptococci and enterococci were detected in both corn and grass samples. However, gram-negative bacteria were not detected. Understanding the potential health effect related to consumption of these bacteria and environmental load remains unknown.

Flow cytometric differential cell counts in milk for the evaluation of inflammatory reactions in clinically healthy and subclinically infected bovine mammary glands. By Schwarz et al., page 5033. Currently, mastitis diagnosis in dairy cows is based on somatic cell counts (SCC) and bacteriological examinations of quarter foremilk samples. In Germany, a threshold of 100,000 cells $/ \mathrm{mL}$ is used to differentiate between healthy and diseased mammary glands. For a more detailed analysis of the health status in mammary glands classified as healthy by SCC, we differentiated the responsible cell populations (lymphocytes, macrophages, polymorphonuclear neutrophilic leukocytes) in quarter foremilk samples using flow cytometry. We found inflammatory reactions in udder quarters at SCC that were well below the current cutoff value of 100,000 cells $/ \mathrm{mL}$.

Effect of mobility score on milk yield and activity in dairy cattle. By Reader et al., page 5045. The hypothesis tested was that delay in treatment of lame cows explains the reduction in milk yield before treatment. Delay in treatment was one likely explanation for a reduction in milk yield. Reduced yield occurred before cows were visibly lame; one explanation is that mobility scoring is less than $100 \%$ sensitive.

Validity of prepartum changes in vaginal and rectal temperature to predict calving in dairy cows. By Burfeind et al., page 5053. Difficult calving is a common problem in dairy herds and has negative effects on the calf and the dam. An accurate prediction of the onset of calving might help to ensure that cows are supervised so that assistance can be provided if needed to reduce calf and cow mortality during calving. The objective was to investigate whether a decrease in vaginal and rectal temperature can be used to predict calving in dairy cows. Dairy cows did exhibit a decrease in body temperature before calving, but detection of this decrease did not predict the onset of calving precisely.

Effect of forage source and a supplementary methionine hydroxy analog on nitrogen balance in lactating dairy cows offered a low crude protein diet. By Whelan et al., page 5080. Nutritional strategies to reduce nitrogen excretion from dairy cows are important for the environment. In this experiment, low crude protein diets (13.3\%), containing either grass silage or corn silage as the main forage source, fed with or without supplementary methionine were offered to lactating dairy cows. Replacing grass silage with corn silage increased nitrogen intake. However, milk nitrogen output and excretion of nitrogen in urine and feces were not affected. Supplementing diets with a methionine source did not alter nitrogen balance.

Effects of encapsulated niacin on metabolism and production of periparturient dairy cows. By Morey et al., page 5090. Niacin, a B-vitamin, has been shown to reduce lipolysis when given at pharmacological levels postruminally. We tested whether an encapsulated form of niacin that can be included in the ration could decrease postpartum lipolysis and reduce the severity of fatty liver, thereby improving metabolic health and liver function. Niacin reduced feed intake before calving, but it limited postpartum lipolysis and tended to decrease liver fat content in primiparous cows. Niacin can be effective at limiting postpartum lipolysis, but effects on feed intake warrant further investigation.

Corn silage versus corn silage:alfalfa hay mixtures for dairy cows: Effects of dietary potassium, calcium, and cation-anion difference. By Erdman et al., page 5105. Corn silage has become the predominant forage used in the dairy industry. Previous studies with dairy cows suggested that diets containing corn silage alone were inferior to those containing at least some alfalfa hay or silage. We believed that this result could be due to the increased potassium, calcium, 
and dietary cation-anion difference (DCAD) in alfalfa. A study was conducted in which corn silage-based diets were supplemented to match the selected minerals and DCAD of a diet with 50:50 mixture of alfalfa hay and corn silage. Milk production and feed efficiency were increased in cows fed mineral-fortified corn-silage diets compared with corn silage alone and were equivalent to or greater than that in cows fed the corn silage:alfalfa hay diet.

Maturation of endogenous glucose production in preterm and term calves. By Steinhoff-Wagner et al., page 5111. Glucose metabolism of preterm or term calves, or calves fed colostrum for $4 \mathrm{~d}$ were studied to observe ontogenetic development. The preterm calves were not able to maintain plasma glucose concentration during first $24 \mathrm{~h}$ of life, although they had the highest glucagon:insulin ratio in plasma. Lowest endogenous glucose production (eGP) and gluconeogenesis in preterm calves indicated an immature eGP and endocrine regulation of eGP. Maturation of gluconeogenesis and eGP depended on ontogenetic development and increased with age in neonatal calves.

Effect of reduced ferulate-mediated lignin/arabinoxylan cross-linking in corn silage on feed intake, digestibility, and milk production. $B y$ Jung et al., page 5124. Corn silage is an important forage for dairy cows, but the stover in silage has a high fiber content and is of limited digestibility. A mutation in corn results in reduced fiber cross-linking and improved laboratory digestibility. In this study, we examined the effect of this mutation on animal performance. Although the mutation did not improve corn silage intake by lambs, selection against corn stover fiber was reduced and amount of fiber digested daily was increased. Holstein cows fed the mutant silage consumed more feed, produced more milk, and had greater fiber digestibility. Corn hybrids incorporating this lowcross-linking mutation should increase the efficiency of milk production.

Ruminal fermentation, milk fatty acid profiles, and productive performance of Holstein dairy cows fed two different safflower seeds. By Dschaak et al., page 5138. A lactation experiment was conducted to determine the effects of supplementing safflower seeds in a dairy diet on ruminal fermentation, productive performance, and milk fatty acid profiles of dairy cows. Feed intake, digestibility, ruminal fermentation, and yields of milk and milk components were not affected by supplementing safflower seeds. However, supplementing diet with safflower seed enhanced milk fat concentrations of C18:1 trans-11 and cis-9,trans-11 conjugated linoleic acid. Supplementing whole safflower seeds in dairy diets at 3\% dry matter can be an effective strategy of fat supplementation to lactating dairy cows without negative effects on lactational performance and milk fatty acid profiles.

Rates of inbreeding and genetic diversity in Canadian Holstein and Jersey cattle. By Stachowicz et al., page 5160. As the loss of genetic diversity is a potential problem in the modern dairy cattle breeds, the pedigrees of Canadian Holsteins and Jerseys were analyzed in order to assess rates of inbreeding and genetic diversity in these two populations. Genetic drift was identified as the main cause of loss of genetic diversity. The genetic base of these populations was found to be narrow, with ancestors with the highest genetic contributions to animals born in recent years being related to each other.

Genetic parameters for female fertility, locomotion, body condition score, and linear type traits in Czech Holstein cattle. By Zink et al., page 5176. The aim of this study was to estimate the heritability of linear type and reproduction traits in first and second lactations, as well as genetic correlations between these traits, in the Czech Holstein cattle population. Reproduction traits had a low heritability but some of the linear type traits had moderate to high heritability and genetic correlation to reproduction traits. This means that it is hard to select for improved reproduction only based on the direct reproduction traits. Genetic selection for improved locomotion and higher body condition scores would lead to enhanced genetic potential for reproduction of lactating Czech Holstein cows.

Genetic analysis of detailed milk protein composition and coagulation properties in Simmental cattle. By Bonfatti et al., page 5183. Heritabilities and genetic correlations for milk protein fraction contents, milk protein composition, and coagulation properties were estimated. These estimates indicate that it is possible to alter milk protein composition through selective breeding. Milk protein genes are responsible for most of the genetic variation of milk protein content. Milk protein composition was genetically associated with coagulation properties of milk. Information on genetic parameters of protein composition is of primary importance to evaluate the implementation of breeding programs aiming to improve milk coagulation properties and cheese yield.

Population structure and effects of inbreeding on milk yield and quality of Murrah buffaloes. By Santana et al., page 5204. The structure of a Murrah buffalo population from southeastern Brazil was investigated by pedigree analysis. Inbreeding generally had a negative effect on milk production and quality traits. A designed mating system to avoid increase of inbreeding should be applied to this population in order to maintain genetic diversity. 
Short communication: A comparison between Holstein and Brown Swiss $\times$ Holstein cows for milk production, somatic cell score, milking speed, and udder measurements in the first 3 lactations. By Bløttner et al., page 5212. Brown Swiss $\times$ Holstein crosses from a designed experiment were not significantly different from purebred Holstein cows for milk yield, fat and protein production, and somatic cell score for the first 3 lactations. However, Brown Swiss $\times$ Holstein crosses had longer milking times and slower milking speeds than purebred Holstein cows in first, second, and third lactations. Furthermore, Brown Swiss $\times$ Holstein crosses had longer teats and less udder clearance than purebred Holstein cows in first and second lactations.

Factors affecting consumers' preferences for and purchasing decisions regarding pasteurized and raw milk specialty cheeses. By Colonna et al., page 5217. Consumers were served pairs of cheeses made from pasteurized and raw milk by the same processor. The consumers in this study preferred cheeses made from raw milk. However, many were concerned about the safety of raw milk cheeses. When informed that raw milk cheeses are produced by an FDA-approved process, most of those concerned changed their mind. Consumers were also asked about what factors affect their willingness to buy cheese. This information will help specialty cheese producers market both pasteurized milk and raw milk cheeses.

Survival characteristics of Salmonella enterica serovar Newport in the dairy farm environment. By Dou et al., page 5238. Understanding the behavior of disease-causing bacteria in animal production systems is vital in maintaining animal health and safeguarding the quality of food for humans. Using environmental sentinel chambers, we studied the persistence of Salmonella in a compost pile, effluent lagoon, and field soil on a dairy farm. Salmonella survived for over 4 mo in the lagoon and $9 \mathrm{mo}$ in soil. In the compost pile, high temperatures (reaching $150^{\circ} \mathrm{F}$ ) eliminated the pathogens within $1 \mathrm{~d}$. Although composting can be highly effective in pathogen control, long-term survival in the soil and lagoon may pose environmental risks when animal manures are applied to the land. 